\title{
Cavernous Carotid Aneurysms in the Era of Flow Diversion: A Need to Revisit Treatment Paradigms
}

\author{
O. Tanweer, E. Raz, A. Brunswick, D. Zumofen, M. Shapiro, H.A. Riina, M. Fouladvand, T. Becske, and P.K. Nelson
}

\begin{abstract}
BACKGROUND AND PURPOSE: Recent techniques of endoluminal reconstruction with flow-diverting stents have not been incorporated into treatment algorithms for cavernous carotid aneurysms. This study examines the authors' institutional experience and a systematic review of the literature for outcomes and complications using the Pipeline Embolization Device in unruptured cavernous carotid aneurysms.
\end{abstract}

\begin{abstract}
MATERIALS AND METHODS: A retrospective search for cavernous carotid aneurysms from a prospectively collected data base of aneurysms treated with the Pipeline Embolization Device at our institution was performed. Baseline demographic, clinical, and laboratory values; intrainterventional data; and data at all follow-up visits were collected. A systematic review of the literature for complication data was performed with inquiries sent when clarification of data was needed.

RESULTS: Forty-three cavernous carotid aneurysms were included in the study. Our mean radiographic follow-up was 2.05 years. On last follow-up, $88.4 \%$ of the aneurysms treated had complete or near-complete occlusion. Aneurysm complete or near-complete occlusion rates at 6 months, 12 months, and 36 months were $81.4 \%, 89.7 \%$, and 100\%, respectively. Of patients with neuro-ophthalmologic deficits on presentation, $84.2 \%$ had improvement in their visual symptoms. Overall, we had a $0 \%$ mortality rate and a $2.3 \%$ major neurologic complication rate. Our systematic review of the literature yielded 227 cavernous carotid aneurysms treated with the Pipeline Embolization Device with mortality and morbidity rates of $0.4 \%$ and $3.1 \%$, respectively.
\end{abstract}

CONCLUSIONS: Endoluminal reconstruction with flow diversion for large unruptured cavernous carotid aneurysms can yield high efficacy with low complications. Further long-term data will be helpful in assessing the durability of the cure; however, we advocate a revisiting of current management paradigms for cavernous carotid aneurysms.

ABBREVIATIONS: $C C A=$ cavernous carotid aneurysm; PED = Pipeline Embolization Device

avernous carotid aneurysms (CCAs) are a distinct form of extradural intracranial aneurysms. The natural history of CCAs has been studied, with the conclusion that these aneurysms have a low risk of causing major morbidity and mortality. ${ }^{1-4}$ However, once they reach the size at which they penetrate or protrude through the dura, they, like other intradural aneurysms, carry the risk of subarachnoid hemorrhage. The overall relatively

Received January 29, 2014; accepted after revision May 13.

From the Departments of Neurosurgery (O.T., A.B., D.Z., P.K.N.), Radiology (E.R., D.Z., M.S., H.A.R., T.B., P.K.N.), and Neurology (M.F., T.B., P.K.N.), New York University School of Medicine, New York, New York.

PED devices were provided free by Chestnut Medical for 16 of the described patients as part of the Pipeline Embolization Device for Uncoilable or Failed Aneurysms trial.

Please address correspondence to Peter K. Nelson, MD, Department of Radiology, New York University School of Medicine, 660 First Ave, New York, NY 10016; e-mail: peter.nelson@nyumc.org

http://dx.doi.org/10.3174/ajnr.A4081 benign natural history has been weighed against traditional treatment options, including surgical clipping, parent artery occlusion with or without bypass, and endovascular coiling, all of which carry varying risks of major morbidity and mortality. The result has shown that expectant management for most CCAs carries a significantly lower risk than treatment, and this has been the standard of care for most CCAs for the past several decades.

The consensus among practitioners has been that CCAs merit treatment only in narrowly defined circumstances (Table 1). ${ }^{1-3}$ Underlying reasons to pursue conservative management also include the low annual rupture rate of CCAs and their tendency to rupture into the cavernous sinus, leading to carotid cavernous fistula formation rather than subarachnoid hemorrhage.

A treatment option that can offer a durable solution with low morbidity and mortality would warrant reconsideration of our current treatment paradigms for CCAs. Recently, flow diversion by using the Pipeline Embolization Device (PED; Covidien, 
Table 1: Generally accepted indications to treat CCAs Indications

Symptomatic CCAs
Symptomatic mass effect (ophthalmoplegia or intractable
retro-orbital pain)
Symptomatic with acute thrombotic changes
Symptomatic or asymptomatic CCAs
Ruptured aneurysms
Bony erosion
Radiographic evidence of projection into subarachnoid space
Underlying coagulopathy
Large aneurysms ( $>10 \mathrm{~mm}$ )
Evidence of growth of aneurysms

Irvine, California $)^{5}$ has been introduced and approved by the FDA for treatment of internal carotid artery aneurysms. In early studies, the PED was considered feasible for deployment in most CCAs, ${ }^{6}$ and since then, many studies have reported its safety and feasibility for the treatment of anterior circulation aneurysms. ${ }^{5,7,8}$ Because the natural history of CCAs is generally favorable, the burden of intervention lies with the success and safety of a device.

We present a single-center study of CCAs treated with the PED and the outcomes and complications. In addition, we review the current literature for morbidity and mortality of CCA treatment with flow diversion. This analysis and accumulation of outcome data may help provide further insight into the ongoing dilemma of management of CCAs.

\section{MATERIALS AND METHODS}

The data for this study were collected prospectively but reviewed retrospectively. Our institutional review board approval was obtained prospectively, as part of a larger study. Informed consent was obtained from all participants; the study was compliant with Health Insurance Portability and Accountability Act regulations. From a larger cohort of 126 consecutive subjects treated before December 2011, 43 patients had treatment of a CCA with a PED. Aneurysms of acute dissecting, traumatic, and infectious etiology were excluded.

We recorded the following baseline demographic, clinical, and laboratory values: age, sex, and baseline neuro-ophthalmologic examination (performed by a neuro-ophthalmologist, M.F.). Intrainterventional data recorded were the location of the aneurysm, the size of the aneurysm, and the number of PEDs deployed. At follow-up, the time interval from the procedure, the complete or partial aneurysm occlusion, and ophthalmologic examination (when clinically pertinent) were recorded.

\section{Treatment Protocol}

Procedures were performed with the patient under general anesthesia by using $6 \mathrm{~F}$ or $7 \mathrm{~F}$ femoral artery access. A $5 \mathrm{~F}$ or $6 \mathrm{~F}$ guidingcatheter system was placed into the distal cervical or horizontal petrous segment of the internal carotid artery. A 0.027-inch-inner-diameter microcatheter (Renegade Hi Flo; Boston Scientific, Natick, Massachusetts or Marksman; Covidien) was then manipulated over a 0.014- to 0.016-inch microwire (Transend-14, Transend-18; Stryker Neurovascular or Headliner-16; Terumo, Tokyo, Japan) into a position across the aneurysm neck. Once the microcatheter was in position, the PED was loaded into the hub of the delivery microcatheter and advanced. The device was then deployed through a technique previously described. ${ }^{6}$ Once deployed, the delivery microcatheter was advanced over the delivery microwire to recapture the microwire and re-establish its position distal to the aneurysm. If needed, additional PEDs were then deployed by using the same technique. Immediate post-treatment angiography was performed in the working projections for PED reconstruction and in the standard angiographic projections. Neurologic status was assessed before treatment, immediately after treatment, and at discharge.

\section{Periprocedural Medications}

Most patients received $75 \mathrm{mg}$ of clopidogrel and $325 \mathrm{mg}$ of acetylsalicylic acid per day starting at least 5 days before the procedure. A small number of patients received loading doses during a 48-hour period, with a minimum total preprocedural clopidogrel dose of $300 \mathrm{mg}$. During the intervention, patients were anticoagulated by an intravenous bolus of heparin sodium (2000-3000 U). Patients continued clopidogrel (75 mg daily) and acetylsalicylic acid (325 mg daily) for a minimum of 180 days after treatment.

\section{Follow-Up Protocol and Imaging Evaluation}

Subjects underwent mandatory clinical follow-up and repeat angiography follow-up to assess aneurysm occlusion, PED positioning, and in-stent stenosis. We considered the longest angiographic follow-up when $>1$ phase of follow-up was available. All angiograms were reviewed by 3 neurointerventionalists. Radiographic outcome was categorized as either complete occlusion, remnant neck (near-complete occlusion), and residual aneurysm. Because no adjunct coils were used, assessment of radiographic outcome was straightforward with 99\% interobserver agreement.

All patients underwent neurologic examination on follow-up visits. The patients who presented with visual symptoms were followed by the Neuro-Ophthamology Department. Complications were grouped into mortality, major morbidity (new postprocedure permanent neurologic deficit), and minor morbidity (transient new deficit).

\section{Systematic Literature Review}

To assess multicenter complication rates with flow diversion, we performed a systematic literature review. On-line data bases MEDLINE (PubMed) and EMBASE were searched for English language articles published up to April 2013 containing the following search terms: "intracranial aneurysms" or "cavernous carotid aneurysms" or "flow diverter" or "flow diversion" or "Pipeline Embolization Device" or "Silk." In addition, bibliographies were examined for additional articles. Inclusion criteria were the following: a series of $\geq 5$ patients who had 1) flow diversion for CCA, 2) clinical follow-up of at least 3 months, and 3) neurologic complication and mortality data. Studies reporting a larger cohort of aneurysms were included if data on outcomes specific to CCAs were available. When applicable, inquiries to senior authors of studies requiring further clarification on CCA data were made. Studies in which most patients were included in another study or reported trial were eliminated.

Results are represented as mean \pm SD. The Fisher exact test 
Table 2: Demographics, patient presentation, and aneurysm characteristics

\begin{tabular}{lc}
\hline & No. or Mean \\
\hline Age (yr) & $57 \pm 14.2$ \\
Female & $83.7 \%(36)$ \\
Presenting symptom & \\
$\quad$ Visual & $65.1 \%(28)$ \\
Headaches & $16.3 \%(7)$ \\
Thromboembolic event & $4.7 \%(2)$ \\
Memory & $2.3 \%(1)$ \\
Facial pain/numbness & $2.3 \%(1)$ \\
Aneurysm maximum diameter (mm) & $24.3 \pm 9.7$ \\
Small, $<10$ mm & 0 \\
Large, $10-25$ mm & 23 \\
Giant, $\geq 25$ mm & 20 \\
Aneurysm neck (mm) & $13.6 \pm 11.6$ \\
Dome-to-neck ratio & $2.2 \pm .9$ \\
\hline
\end{tabular}

was used for comparison of categoric data, given our sample size. $P$ values $<.05$ were statistically significant.

\section{RESULTS}

At our institution, 43 CCAs treated with PEDs were included in our study. These cases represented a consecutive cohort of CCAs treated with PEDs up to December 2011. Sixteen of these patients were included in the Pipeline Embolization Device for Uncoilable or Failed Aneurysms study. ${ }^{7}$

\section{Baseline Patient and Aneurysm Characteristics}

Forty-three CCAs were present in 41 patients. The average age of the patient was $57 \pm 14.2$ years old, and $84.1 \%$ were female $(n=36)$. None of these aneurysms were ruptured. The major presenting symptoms were ophthalmologic (diplopia, visual field deficits, or change in visual acuity) in $65 \%$ of the patients, headaches in $16.3 \%$, and incidental findings in $9.3 \%$. Most aneurysms were large with wide necks. The average maximum diameter of the treated CCAs was $24.3 \pm 9.7 \mathrm{~mm}$; the aneurysm neck was $13.6 \pm 11.6 \mathrm{~mm}$. The dome/neck ratios were $2.2 \pm 0.88$. Three of the aneurysms were treated previously with coils, Onyx embolization (Covidien), and coil plus stent, respectively. Partial thrombosis was noted in $25.6 \%(n=11)$ of patients (Table 2 ).

\section{Procedural Specifics}

A total of 165 PEDs were deployed in the treatment of the 43 aneurysms. On average, $3.8 \pm 2.1$ PEDs were used per aneurysm, and no patient was treated with a single PED (range, 2-10). During this period, the longest PED available was 20 $\mathrm{mm}$, partially accounting for the high PED/aneurysm ratio. All PEDs were deployed without complications, and no instance of PED retraction into the aneurysm sac, dissection, or device migration was noted. An intraoperative ipsilateral subarachnoid hemorrhage was encountered in 1 patient. An avulsion of a small branch arising from the angular division of the right middle cerebral artery with slow extravasation of contrast was seen on angiography, and a parenchymal and Sylvian hematoma was revealed by intraprocedural conebeam CT. This likely was the result of a wire perforation during an exchange technique to bypass the aneurysm neck. The bleeding was controlled with deconstructive embolization with Guglielmi de- tachable coils (Stryker Neurovascular), leading to hemostasis documented by follow-up CT. The patient was discharged to a subacute nursing facility, and her 1-year mRS was 3 .

Adjunctive treatments included coil embolization ( 1 case) and balloon angioplasties. The single adjunctive coil embolization was performed to obtain distal access through the complex aneurysm neck, where 9 coils were placed and used to deflect the Marksman catheter away from the aneurysm dome. Adjunctive balloon angioplasties, however, were more often used in $32.6 \%$ of patients $(n=14)$. The goal of balloon angioplasty was either to dilate severely stenotic perianeurysmal segments of the ICA before PED delivery or, in most instances, to appose the device against the vessel wall in cases in which incomplete device opening was noted, especially in case of excessively tortuous anatomy. No instance of vessel injury, dissection, or rupture was experienced during or after balloon angioplasty. An additional indication for balloon use was as an anchor for distal microcatherization of the parent vessel in 1 case.

\section{Radiographic Follow-Up and Clinical Outcomes}

Our mean radiographic follow-up was 2.05 years (range, 0.5-3.5 years). All radiographic follow-up was with DSA except for 1 patient in whom CTA was performed. On last follow-up of all patients, $76.7 \%$ had complete occlusion of the aneurysm, $11.6 \%$ had entry/neck remnant, and $11.6 \%$ had residual filling of their aneurysm. Therefore, $88.4 \%$ of the aneurysms treated had complete or near-complete occlusion on last follow-up (See Fig 1 for a representative case). Aneurysm complete or near-complete occlusion rates at 6,12 , and 36 months were $81.4 \%, 89.7 \%$, and $100 \%$, respectively (Fig 2). No migration of PEDs on follow-up studies was noted. In-stent stenosis higher than $50 \%$ was found in 3 of 43 patients at 6-month follow-up, and an additional case of stenosis was found at 1-year follow-up. All of these cases were asymptomatic complete occlusion of the parent vessel along with the aneurysm. In addition, there was no instance of aneurysm expansion in our series.

As mentioned above, 1 instance of major neurologic morbidity was encountered during the periprocedural phase. No other major neurologic morbidity or mortality was reported during our follow-up period. Overall, we had a $0 \%$ mortality rate and a $2.3 \%$ major neurologic complication rate. Three cases of transient neurologic deficits were encountered. One of these was a small ipsilateral frontal hematoma found at 3 days postprocedure. Of the 19 patients who had neuro-ophthalmologic evaluation before PED placement and continuing follow-up afterward, $84.2 \%$ had improvement in their visual symptoms; the rest had no improvement and none had worsening. In addition, there were no cases of SAH after treatment during our follow-up. One case of carotid cavernous fistula was found on 6-month follow-up, presenting as tinnitus on posttreatment day 1; however, the patient did not report this symptom.

\section{Systematic Literature Review}

Sixteen studies met our inclusion criteria of having at least 5 patients with CCAs in which morbidity and mortality data for that cohort were available and at least 3-month follow-up to ensure that any delayed complications were included. The se- 


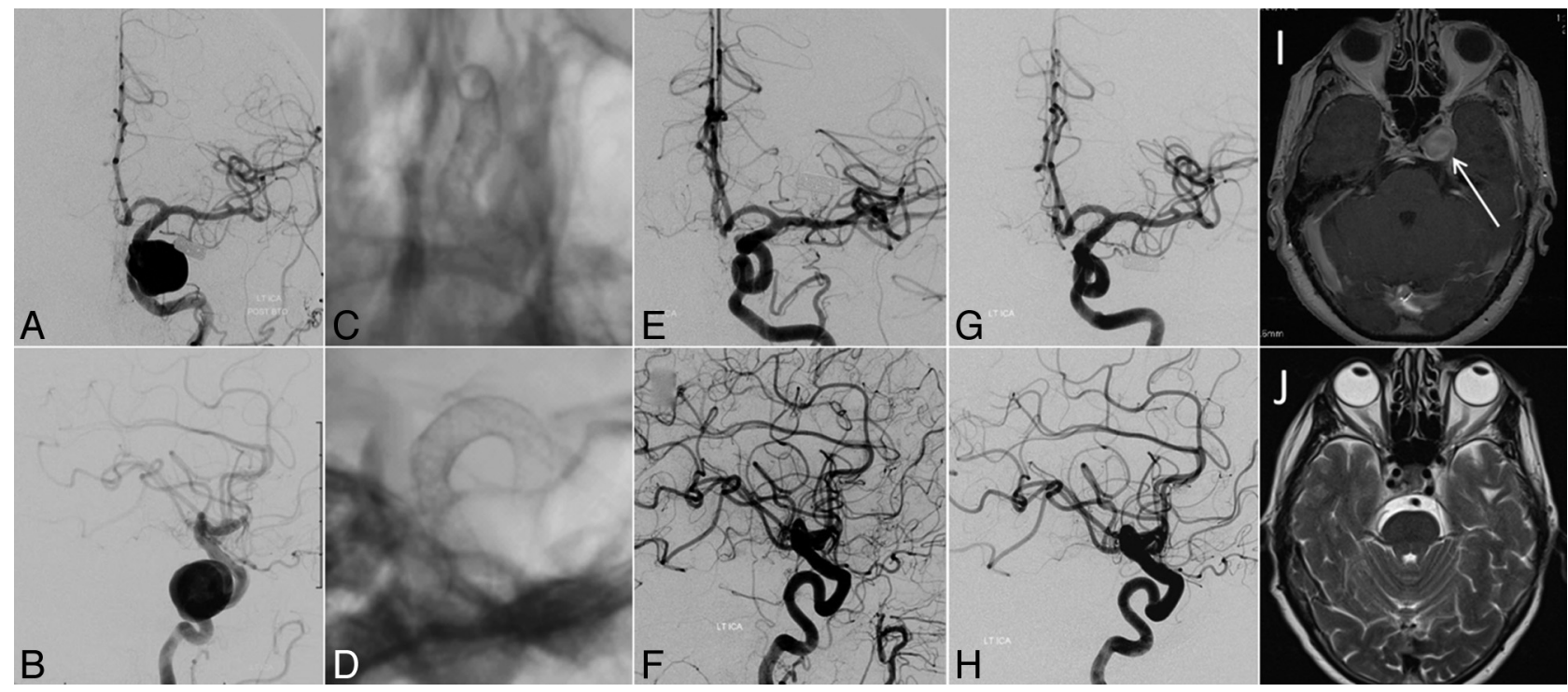

FIG 1. A 65-year-old woman who presented with progressive left-sided ophthalmoparesis due to third and fourth cranial nerve palsy. Digital subtraction angiography in frontal $(A)$ and lateral $(B)$ views demonstrates a large (19-mm-diameter) aneurysm arising from the cavernous segment of the left internal carotid artery. The patient was treated by endoluminal reconstruction of the LICA with 3 overlapping PEDs (frontal, C, and lateral, $D$ ). One-year follow-up digital subtraction angiography in frontal $(E)$ and lateral $(F)$ views and 5-year follow-up digital subtraction angiography in frontal $(G)$ and lateral $(H)$ views confirm stable angiographic cure. Regression of symptoms was correlated with the resolution of aneurysm mass effect as illustrated by comparison of the pretreatment gadolinium-enhanced axial T1-weighted MR image (I, white arrow) with the 5-year follow-up axial T2-weighted MR image ()).

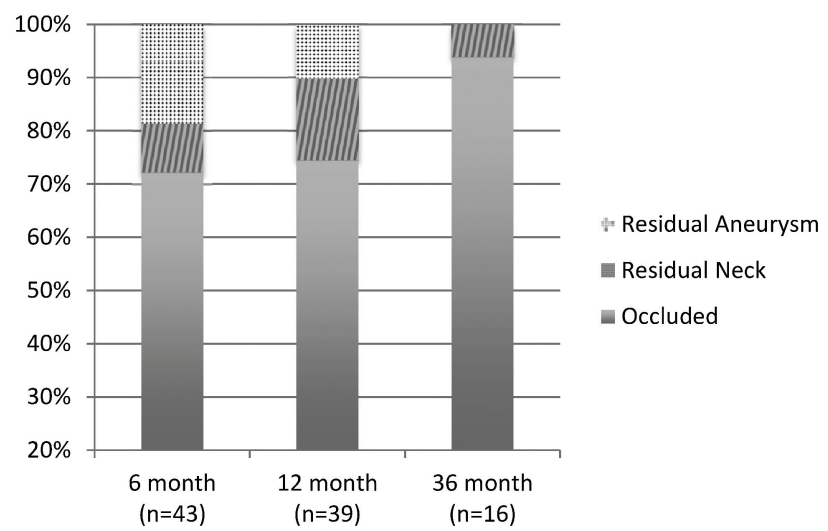

FIG 2. Radiographic outcomes at 6, 12, and 36 months.

nior authors of 6 studies were e-mailed for further clarification of their data, with an $83 \%$ response rate with further helpful delineation of their data (Table 3). When we included our data, 296 CCAs treated with flow diversion were found in the literature. A cumulative major morbidity rate was $4.1 \%$, and the mortality rate was $0.7 \%$. A subanalysis looking at studies that used the PED found the morbidity and mortality rates to be only $3.1 \%$ and $0.44 \%$, respectively. Studies in which only a Silk flow-diverter stent (Balt Extrusion, Montmorency, France) was used had morbidity and mortality rates of $7.5 \%$ and $1.9 \%$, respectively. The greater morbidity seen in Silk studies compared with PED studies trended toward but did not meet statistical significance $(P=.063)$.

\section{DISCUSSION}

In our series of 43 CCAs, we achieved complete or near-complete occlusion of the aneurysm in $88.4 \%$ of the patients at last followup. By 3 years, 100\% of the followed aneurysms achieved com-
Table 3: Systematic review of the literature for flow diversion of CCAs

\begin{tabular}{|c|c|c|c|c|c|}
\hline Study & $\begin{array}{c}\text { Total } \\
\text { Aneurysms } \\
\text { in Study }\end{array}$ & $\begin{array}{l}\text { Silk or } \\
\text { PED }\end{array}$ & $\begin{array}{l}\text { CCAs } \\
\text { (No.) }\end{array}$ & $\begin{array}{l}\text { Major } \\
\text { Morbidity } \\
\text { (No.) }\end{array}$ & $\begin{array}{c}\text { Mortality } \\
\text { (No.) }\end{array}$ \\
\hline Berge et $\mathrm{al}^{29}$ & 77 & Silk & 29 & 3 & 0 \\
\hline Becske et $\mathrm{al}^{7, \mathrm{a}}$ & 108 & PED & 28 & 1 & 0 \\
\hline Chan et $\mathrm{al}^{30}$ & 13 & PED & 5 & 0 & 0 \\
\hline Chitale et $\mathrm{al}^{31}$ & 42 & PED & 16 & 2 & 0 \\
\hline Cinar et $\mathrm{al}^{32}$ & 55 & PED & 5 & 0 & 0 \\
\hline Fischer et $\mathrm{al}^{33, \mathrm{~b}}$ & 101 & PED & 15 & 1 & 0 \\
\hline Lubicz et al ${ }^{34}$ & 34 & Silk & 5 & 1 & 0 \\
\hline Lylyk et $\mathrm{al}^{5}$ & 63 & PED & 11 & 0 & 0 \\
\hline McAuliffe et $\mathrm{al}^{35, c}$ & 57 & PED & 11 & 0 & 0 \\
\hline Nelson et al ${ }^{6}$ & 31 & PED & 5 & 0 & 0 \\
\hline O'Kelly et al ${ }^{8}$ & 94 & PED & 28 & 0 & 0 \\
\hline Piano et $\mathrm{al}^{36}$ & 104 & $\begin{array}{l}\text { Silk } \\
\text { PED }\end{array}$ & 16 & 1 & 0 \\
\hline Saatci et $\mathrm{al}^{37}$ & 251 & PED & 28 & 1 & 0 \\
\hline Velioglu et $\mathrm{al}^{38, \mathrm{~d}}$ & 87 & Silk & 19 & 0 & 1 \\
\hline Yu et $a^{27, e}$ & 178 & PED & 32 & 1 & 1 \\
\hline Current study & 43 & PED & 43 & 1 & 0 \\
\hline \multirow[t]{3}{*}{ Total } & 1338 & & 296 & $12(4.1 \%)$ & $2(0.7 \%)$ \\
\hline & & PED only & 227 & $7(3.1 \%)$ & $1(0.44 \%)$ \\
\hline & 0.68 & Silk only & 53 & $4(7.5 \%)$ & $1(1.9 \%)$ \\
\hline
\end{tabular}

${ }^{a}$ T. Becske, MD, personal oral communication, April 2013.

${ }^{\mathrm{b}} \mathrm{H}$. Henkes, MD, personal e-mail communication, April 2013.

cW. McAuliffe, MD, personal e-mail communication, April 2013.

${ }^{d}$ N. Kocer, MD, personal e-mail communication, April 2013.

e S.C. Yu, MD, personal e-mail communication, April 2013.

plete or near-complete occlusion. This was achieved with $0 \%$ mortality and a $2.3 \%$ major neurologic complication rate. In addition, $84.2 \%$ of the patients with ophthalmologic follow-up had improvement of their presenting visual symptoms. In our systematic review, which included studies from many different centers and countries, the mortality and morbidity rates for treatment of CCAs with PED were $0.44 \%$ and $3.1 \%$, respectively.

AJNR Am J Neuroradiol 35:2334-40 Dec 2014 www.ajnr.org 


\section{Natural History of Cavernous Carotid Aneurysms}

CCAs, especially when small, rarely rupture. Larger CCAs ( $>13$ $\mathrm{mm}$ ) had a 5-year rupture rate of 9.4\% in the International Study of Unruptured Intracranial Aneurysms trial. ${ }^{4}$ When they do rupture, they typically rupture into the cavernous sinus, which leads to carotid cavernous fistula formation. Such a development is far less catastrophic than rupture of intradural aneurysms. However, although rare, SAH from rupture of a CCA with a small intradural component does occur. ${ }^{1}$ Unfortunately current imaging is usually unable to clearly distinguish these more dangerous CCAs. ${ }^{9}$ There have also been rare case reports of fatal SAH in CCAs judged to be entirely intracavernous. ${ }^{10}$

Several studies have followed the natural history of treated and untreated cohorts of patients with CCA. Stiebel-Kalish et $\mathrm{al}^{3}$ have published the largest retrospectively reviewed cohort of patients with CCAs. Of 185 patients with CCAs, 74 were treated due to refractory pain, carotid cavernous fistula, sphenoid erosion, diplopia, and compressive optic neuropathy. Among treated patients, pain resolved in $96 \%$ of cases. There was no considerable improvement in diplopia, though $61 \%$ of patients experienced resolution of symptoms. Of the 111 untreated patients, $2 \%$ had stroke, $1 \%$ had SAH, $1 \%$ had carotid cavernous fistula formation, and $6 \%$ developed compressive optic neuropathy; these represented a cumulative 10\% adverse event occurrence rate. Quality of life symptoms such as neuro-ophthalmic and refractory pain each resolved spontaneously in 56\% of these patients. Moreover, approximately one-third of the untreated patients who were asymptomatic developed symptoms during the course of their 4-year follow-up. The authors also found that those treated by endovascular means (by using preferred methods during a 21-year period) were more likely to experience complications than those not treated. The authors conclude, therefore, that because the risk for major neurologic complications, even in experienced hands, was in the range of $5 \%-9 \%$, the indications for treatment of CCAs should be carefully considered in each individual case. ${ }^{3}$

Not all studies have come to the same conclusion: A 2003 study compared 21 patients treated for CCAs by using the technology available at the time with 10 not treated and sought to compare outcomes. In the 10 patients followed without intervention, none improved spontaneously, 3 remained the same, and 7 worsened. As a result, the author advocated stronger consideration for treatment. ${ }^{11}$

\section{Treatment Options and Outcomes}

Much of the support for the current treatment paradigm is based on the high morbidity and mortality from previously available options for surgical and endovascular intervention. Treatment options are divided into deconstructive and reconstructive approaches. Deconstructive approaches include occlusion of the parent artery with or without a vascular bypass. Reconstructive or constructive approaches aim to preserve the parent artery and include microsurgical clipping, endovascular coiling with or without stents, and now flow diversion with a PED or similar device. Several cohorts of microsurgical clipping have been reported, and even in the best hands, clipping is understandably accompanied by a morbidity and mortality ranging from $14 \%$ to $25 \% .{ }^{12-17}$ Studies of microsurgical carotid occlusion (Hunterian strategies) showed the procedure to be safer, but it still had 9\%$22 \%$ morbidity and mortality rates. ${ }^{13,14,16,18}$

Studies using endovascular deconstructive carotid occlusion have reported a morbidity and mortality rate ranging from $3 \%$ to $8 \%{ }^{19-23}$ More recently, van Rooij ${ }^{24}$ published his single-center experience with endovascular treatment of CCAs, which demonstrated a low complication rate and high clinical improvement rate. Most procedures being performed were endovascular parent artery occlusion without bypass. During the 15-year span of experience, only $5.8 \%$ of the patients had bypasses performed before parent vessel occlusion and approximately $18 \%$ of the total CCAs considered for treatment were instead managed conservatively after patients failed balloon test occlusion and did not want to pursue bypass surgery. It is unclear what the follow-up in those $18 \%$ of patients was. In another large series of CCAs with Hunterian occlusion, up to $20 \%$ required bypass surgery to augment flow. ${ }^{18}$

Although endovascular parent artery occlusion is a relatively easy and inexpensive technique with low morbidity in a selected population, the long-term consequences of altered hemodynamics should be considered. De novo contralateral aneurysm formation is a known sequela of parent artery occlusion, and in a study of case series, there was a $4.5 \%$ incidence of new aneurysm formation contralateral to the carotid occlusion at a mean time of 9 years. ${ }^{25}$ There was a propensity for large anterior communicating artery flow-related aneurysm formation, which, in the setting of an already occluded ICA, can be a very challenging clinical problem. Because recent treatment outcomes are nearing very low morbidity and mortality $(0 \%-2.3 \%)$, the incidence of contralateral aneurysm formation is of important consideration. For these reasons, we advocate preserving normal vascular anatomy whenever possible.

\section{Flow Diversion for CCAs}

Numerous cohorts of patients with intracranial aneurysms treated with PEDs have been published in the past several years. A recent meta-analysis of 1654 intracranial aneurysms showed occlusion rates of $76 \%$ and procedure-related morbidity and mortality to be $5 \%{ }^{26}$ This analysis included posterior circulation aneurysms, which are now well-known to contribute considerable morbidity and mortality. Larger studies stratified by aneurysm location showed that the risk in patients with CCA is low. All studies included in our systematic review reported lower rates of morbidity and mortality compared with their original cohort. In addition, many studies have reported higher occlusion rates among CCA subgroups. ${ }^{6,27}$ This extra success afforded to the cavernous segment is likely multifold. Even though this carotid segment is usually tortuous, there were no major bifurcations occurring on it, which resulted in lower wall sheer stress on the vessel wall and less blood flow through the stent. This result likely decreases the chances of an inflow jet and causes more stasis in the aneurysm.

\section{Treatment Paradigms}

The high rate of major morbidity and mortality from available treatment options in 2009 led Eddleman et al $^{1}$ to elucidate a treatment paradigm widely in use today. This paradigm states that the following CCAs merit treatment: large lesions; symptomatic lesions with acute thrombotic changes; aneurysms with evidence of 
growth; symptomatic lesions with mass effect (ophthalmoplegia) or intractable retro-orbital pain; those with considerable local bone erosion due to risk of fatal epistaxis from rupture; lesions with evidence of projection into the subarachnoid space, which usually cannot be demonstrated; ruptured aneurysms with carotid cavernous fistula, which can rarely lead to intracerebral hemorrhage and ocular ischemia ${ }^{28}$; and CCAs in any patient with an underlying coagulopathy. ${ }^{1}$

With the advent of flow diversion, we now have a new and lowered benchmark for treatment risk. This information should play a critical role in patient discussion of expectant management. Patients who present with smaller CCAs and are asymptomatic should understand the benign natural history of their aneurysms. However, these aneurysms have a possibility of growing, and up to one-third of the time, they may become symptomatic. ${ }^{3}$ Clinical symptoms, especially when long-standing, may not be relieved with conservative management and can leave the patient with permanent deficits. Smaller CCAs can be treated with less technical difficulty in catheter navigation and PED deployment. Although we do not advocate treatment of small and asymptomatic CCAs, an informed discussion should take place with the patient about all options, and the psychological impact of the diagnosis on the patient should also be considered.

Our institutional preference is to use flow diversion for most unruptured symptomatic CCAs of any size unless they have favorable morphology for complete coil occlusion without stent placement and asymptomatic large complex CCAs, especially in younger patients. Other treatment options such as parent artery occlusion without or with bypass and coil embolization with possible balloon assistance are still reserved for consideration in patients in whom long-term antiplatelet therapy is contraindicated or when other considerations make these options more favorable. The authors believe this is the time for the neurointerventional community to develop a new treatment paradigm for CCAs in the face of favorable outcomes from flow diversion.

\section{Limitations}

This study has several important limitations. Although data were collected prospectively, retrospective review imparts inherent bias. In addition, our institutional bias to treat CCAs with flow diversion when possible can skew outcomes. Because during the study period, a limited amount of stent-assisted coiling of CCAs took place, there is no internal cohort with whom to compare our data. Our systematic review also has several limitations: namely, publication bias, heterogeneity of studies, and the retrospective nature of the studies included.

\section{CONCLUSIONS}

CCAs have long been considered benign lesions, but even completely extradural CCAs can have catastrophic complications in a small percentage of patients. Unfortunately, these complications are heterogeneous and difficult to anticipate. Any intervention considered in such a setting must have an even lower risk profile than the natural history of the condition being treated. All previous treatment options for CCAs were clearly shown to be more risky for all but a certain small subset of patients with CCA with predictable high-risk profiles. As a result, previous treatment par- adigms have been constructed to address only patients at high risk and may fail to offer treatment to patients of moderate risk. We believe that the evidence showing the safety and efficacy of the PED, especially for treating CCAs, merits reconsideration of this existing treatment paradigm.

Disclosures: Andrew Brunswick—OTHER RELATIONSHIPS: I am a neurosurgery resident at New York University, and one of our mentors is Peter K. Nelson (in this article), who helped develop the Pipeline Embolization Device. Daniel ZumofenRELATED: Grant: Helmut Hartweg Foundation, Swiss Academia of Medical Sciences, Comments: personal scholarship. Maksim Shapiro-UNRELATED: Consultancy: Covidien, Comments: I am a proctor and consultant for Covidien, the manufacturer of the Pipeline Embolization Device; Grants/Grants Pending: I received Pipeline Embolization Devices from Covidien for benchtop research; Payment for Development of Educational Presentations: I am a proctor and consultant for Covidien, the manufacturer of the Pipeline Embolization Device. Mohammad Fouladvand-RELATED: Consulting Fee or Honorarium: Covidien; UNRELATED: Consultancy: Covidien. Tibor Becske-RELATED: Consulting Fee or Honorarium: Covidien; Support for Travel to Meetings for the Study or Other Purposes: Covidien; UNRELATED: Consultancy: Covidien; Payment for Lectures (including service on Speakers Bureaus): Covidien; Payment for Development of Educational Presentations: Covidien. Peter K. Nelson—UNRELATED: Consultancy: Covidien, Comments: fees for PED proctoring and activities.

\section{REFERENCES}

1. Eddleman CS, Hurley MC, Bendok BR, et al. Cavernous carotid aneurysms: to treat or not to treat? Neurosurg Focus 2009;26:E4

2. Kupersmith MJ, Stiebel-Kalish H, Huna-Baron R, et al. Cavernous carotid aneurysms rarely cause subarachnoid hemorrhage or major neurologic morbidity. J Stroke Cerebrovasc Dis 200211:9-14

3. Stiebel-Kalish H, Kalish Y, Bar-On RH, et al. Presentation, natural history, and management of carotid cavernous aneurysms. Neurosurgery 2005;57:850-57

4. Wiebers D. Unruptured intracranial aneurysms: natural history, clinical outcome, and risks of surgical and endovascular treatment. Lancet 2003;362:103-10

5. Lylyk P, Miranda C, Ceratto R, et al. Curative endovascular reconstruction of cerebral aneurysms with the pipeline embolization device: the Buenos Aires experience. Neurosurgery 2009;64:632-42, discussion 642-43, quiz N6

6. Nelson PK, Lylyk P, Szikora I, et al. The Pipeline embolization device for the intracranial treatment of aneurysms trial. AJNR Am J Neuroradiol 2011;32:34-40

7. Becske T, Kallmes DF, Saatci I, et al. Pipeline for uncoilable or failed aneurysms: results from a multicenter clinical trial. Radiology 2013;267:858-68

8. O'Kelly CJ, Spears J, Chow M, et al. Canadian experience with the Pipeline embolization device for repair of unruptured intracranial aneurysms. AJNR Am J Neuroradiol 2013;34:381-87

9. Shapiro M, Becske T, Riina HA, et al. Toward an endovascular internal carotid artery classification system. AJNR Am J Neuroradiol 2014;35:230-36

10. Lee AG, Mawad ME, Baskin DS. Fatal subarachnoid hemorrhage from the rupture of a totally intracavernous carotid aneurysm: case report. Neurosurgery 1996;38:596-98, discussion 598-99

11. Goldenberg-Cohen N. Long term visual and neurological prognosis in patients with treated and untreated cavernous sinus aneurysms. J Neurol Neurosurg Psychiatry 2004;75:863-67

12. Dolenc V. Direct microsurgical repair of intracavernous vascular lesions. J Neurosurg 1983;58:824-31

13. Dolenc VV. Extradural approach to intracavernous ICA aneurysms. Acta Neurochir Suppl 1999;72:99-106

14. Heros RC. Thromboembolic complications after combined internal carotid ligation and extra- to-intracranial bypass. Surg Neurol 1984;21:75-79

15. Heros RC, Nelson PB, Ojemann RG, et al. Large and giant paraclinoid aneurysms: surgical techniques, complications, and results. Neurosurgery 1983;12:153-63 
16. Jafar JJ, Huang PP. Surgical treatment of carotid cavernous aneurysms. Neurosurg Clin N Am 1998;9:755-63

17. Swearingen B, Heros RC. Common carotid occlusion for unclippable carotid aneurysms: an old but still effective operation. $\mathrm{Neu}$ rosurgery 1987;21:288-95

18. Drake CG, Peerless SJ, Ferguson GG. Hunterian proximal arterial occlusion for giant aneurysms of the carotid circulation. J Neurosurg 1994;81:656-65

19. Niiro M, Shimozuru T, Nakamura K, et al. Long-term follow-up study of patients with cavernous sinus aneurysm treated by proximal occlusion. Neurol Med Chir (Tokyo) 2000;40:88-96, discussion 96-97

20. Parkinson RJ, Eddleman CS, Batjer HH, et al. Giant intracranial aneurysms: endovascular challenges. Neurosurgery 2006;59(5 suppl 3):S103-12, discussion S3-13

21. Ponce FA, Albuquerque FC, McDougall CG, et al. Combined endovascular and microsurgical management of giant and complex unruptured aneurysms. Neurosurg Focus 2004;17:E11

22. van der Schaaf IC, Brilstra EH, Buskens E, et al. Endovascular treatment of aneurysms in the cavernous sinus: a systematic review on balloon occlusion of the parent vessel and embolization with coils. Stroke 2002;33:313-18

23. Yonas $\mathrm{H}$, Kaufmann A. Combined extracranial-intracranial bypass and intraoperative balloon occlusion for the treatment of intracavernous and proximal carotid artery aneurysms. Neurosurgery 1995;36:1234

24. van Rooij WJ. Endovascular treatment of cavernous sinus aneurysms. AJNR Am J Neuroradiol 2012;33:323-26

25. Arambepola PK, McEvoy SD, Bulsara KR. De novo aneurysm formation after carotid artery occlusion for cerebral aneurysms. Skull Base 2010;20:405-08

26. Brinjikji W, Murad MH, Lanzino G, et al. Endovascular treatment of intracranial aneurysms with flow diverters: a meta-analysis. Stroke 2013;44:442-47

27. Yu SC, Kwok CK, Cheng PW, et al. Intracranial aneurysms: midterm outcome of Pipeline embolization device-a prospective study in 143 patients with 178 aneurysms. Radiology 2012;265:893-901

28. van Rooij WJ, Sluzewski M, Beute GN. Ruptured cavernous sinus aneurysms causing carotid cavernous fistula: incidence, clinical presentation, treatment, and outcome. AJNR Am J Neuroradiol 2006;27:185-89

29. Berge J, Biondi A, Machi P, et al. Flow-diverter Silk stent for the treatment of intracranial aneurysms: 1-year follow-up in a multicenter study. AJNR Am J Neuroradiol 2012;33:1150-55

30. Chan TT, Chan KY, Pang PK, et al. Pipeline embolisation device for wide-necked internal carotid artery aneurysms in a hospital in Hong Kong: preliminary experience. Hong Kong Med J 2011;17: 398-404

31. Chitale R, Gonzalez LF, Randazzo C, et al. Single center experience with Pipeline stent: feasibility, technique, and complications. Neurosurgery 2012;71:679-91, discussion 691

32. Çinar C, Bozkaya H, Oran I. Endovascular treatment of cranial aneurysms with the Pipeline flow-diverting stent: preliminary midterm results. Diagn Interv Radiol 2013;19:154-64

33. Fischer S, Vajda Z, Aguilar Perez M, et al. Pipeline embolization device (PED) for neurovascular reconstruction: initial experience in the treatment of 101 intracranial aneurysms and dissections. Neuroradiology 2012;54:369-82

34. Lubicz B, Collignon L, Raphaeli G, et al. Flow-diverter stent for the endovascular treatment of intracranial aneurysms: a prospective study in 29 patients with 34 aneurysms. Stroke 2010;1:2247-53

35. McAuliffe W, Wycoco V, Rice $\mathrm{H}$, et al. Immediate and midterm results following treatment of unruptured intracranial aneurysms with the Pipeline embolization device. AJNR Am J Neuroradiol 2012;33:164-70

36. Piano M, Valvassori L, Quilici L, et al. Midterm and long-term follow-up of cerebral aneurysms treated with flow diverter devices: a single-center experience. J Neurosurg 2013;118:408-16

37. Saatci I, Yavuz K, Ozer C, et al. Treatment of intracranial aneurysms using the Pipeline flow-diverter embolization device: a single-center experience with long-term follow-up results. AJNR Am J Neuroradiol 2012;33:1436-46

38. Velioglu M, Kizilkilic O, Selcuk $\mathrm{H}$, et al. Early and midterm results of complex cerebral aneurysms treated with Silk stent. Neuroradiology 2012;54:1355-65 